\title{
President's Message: Reflections on Membership
}

A s I write my first President's Message for ITAL, I am wrapping up my year as vice president and the ALA Annual Conference is fast approaching. The past year has been a busy one-handling necessary division business, including meeting with my fellow ALA vice presidents, making committee appointments, planning an orientation for new board members, strategic planning, and attending various conferences and meetings to prepare me for my role as LITA president. I am lucky to follow such wonderful leaders as Karen Starr and Michelle Frisque, who have both helped ready me for the year ahead.

My life outside of LITA has been equally busy. I started a new position as the director of Weill Cornell Medical College Library earlier this year and have a busy home life with two small children. As usual, I have been juggling quite a bit and often dropping a few balls. My mantra is that it is impossible to keep all the balls in the air all of the time, but when they do drop be careful not to let them roll so far away from you so that you lose sight of them. Eventually I pick them up and start juggling again.

I know that I am not alone in this juggling exercise. LITA members have real jobs and friends, family, and other social responsibilities that keep us busy. So why do we give so much to our profession, including LITA? If you are like me, it is because we get so much in return. The importance of activity and leadership in national, professional associations cannot be overrated. My experience in LITA and other professional library associations has given me an opportunity to hone leadership skills working with various committees and boards over the years. The achievements that I have made in my career have a direct correlation to my work with LITA. As libraries flatten organizational structures, LITA is one place where anyone can take on leadership roles, gaining valuable experience. Many members have agreed to take on leadership roles in the coming year by volunteering for committees and taskforces and accepting various appointments and I want to thank everyone who came forward. In the coming year I will be working with several officers and committees to develop orientations, mentoring initiatives, and leadership training for our members.

I do appreciate that not everyone wants to take on a leadership role in LITA. The networking opportunities, both formal and informal, also have been extremely valuable in my career. The people I have met in LITA have become colleagues I am comfortable turning to for advice

Colleen Cuddy (colleen.cuddy@med.cornell.edu) is LITA President 2011-12 and Director of the Samuel J. Wood Library and C. V. Starr Biomedical Information Center at Weill Cornell Medical College, New York, New York on technology and other decisions in my career. I know that I can post a question to LITA-L or ALA Connect and get a quick, diverse response to an inquiry. I know that I can call on my LITA colleagues to serve as references and reviewers as I move through my career. I also know that I can depend upon LITA to help keep me current and well informed about technology and how it is integrated into our libraries and lives. This also gives me an edge in my career.

So much of the LITA experience is currently gained from attending meetings in person and making connections - those of you who have attended the LITA Happy Hour can probably attest to this. For several years LITA has not had a requirement to attend meetings in person and allows for virtual participation in committees and interest groups. Several ad hoc methods have developed to allow members to attend meetings virtually. To better institutionalize the process two new taskforces have been formed to look at virtual participation in formal and informal LITA meetings. A broadcasting taskforce is charged with making a recommendation on the best ways to deliver business meetings and another taskforce is charged with investigating methods to deliver education and programming to members virtually. Both taskforces will pay careful attention to interaction and other attributes of in person gatherings that can be applied to virtual meetings so that we retain the connection-making experience.

It is hard to assign monetary value to membership in an association, but we do so every time we make a decision to join or renew membership. When I renew and pay annual dues to LITA I affirm that I am receiving value, and I do so without thinking. It is a given that I will renew. In addition to my library memberships I am a member of the Wildlife Conservation Society (the group behind the Bronx Zoo and several other zoos in NYC). Each year as I renew my membership I do a quick cost analysis calculating how many times I visited the zoos and what it would have cost my family if we were not members. But before I can finish that exercise my mind begins to wander and I start to think about the excursions to the zoos-- camel rides, newborn animals-and those experiences and the memories created derail any cost recovery exercise. It is impossible to put monetary value on the wonderful experiences my family share during our visits to the zoo (incidentally it is more economical as well). I also feel some pride in contributing to an organization that does such wonderful programming and makes a real difference for animals and our planet. I understand that my membership helps them do what they do best. I don't do this cost analysis with LITA, but perhaps I should.

The current price of LITA membership is sixty dollars per year, which is about sixteen cents per day. As members we need to ask ourselves if we are receiving in return what

Continued on page 89 
.youtube.com/watch?v=Sps6C9u7ras. Sadly, the rest of us must borrow or rent a copy.

2. Marc Truitt, "No More Silver Bullets, Please," Information Technology \& Libraries 29, no. 2 (June 2010), http://www.ala .org/ala/mgrps/divs/lita/publications/ital/292010/2902jun/ editorial.cfm (accessed July 13, 2011).

3. Begin with Fforde's The Eyre Affair (2001) and proceed from there. If you are a librarian and are not quickly enchanted, you probably should consider a career change very soon! Thank you, Michele N!

\section{President's Message continued from page 86}

we give to the organization. The LITA Assessment and Research Committee recently surveyed membership to find out why people belong to LITA, this is an important step in helping LITA provide programming etc. that will be most beneficial to its users, but the decision on whether to be a LITA member I believe is more personal and doesn't rest on the fact that a particular Drupal class is offered or that a particular speaker is a member of the Top Tech Trends panel. It is based on the overall experience that you have as a member, the many little things. I knew in just a few minutes of attending my first LITA open house 12 years ago that I had found my ALA home in LITA. I wish that everyone could have such a positive experience being a member of LITA. If your experience is less than positive how can it be more so? What are we doing right? What could we do differently? Please let me or another officer know, and/or volunteer to become more involved and create a more valuable experience for yourself and others. 